\title{
Parametric studies on split S-shaped composite meta atom for X-band communication
}

\author{
M.M. HASAN ${ }^{1}$, M.R.I. FARUQUE ${ }^{1 *}$, and M.T. ISLAM ${ }^{2}$ \\ ${ }^{1}$ Space Science Centre (ANKASA), Universiti Kebangsaan Malaysia, Bangi 43600, Malaysia \\ ${ }^{2}$ Department of Electrical, Electronic, and Systems Engineering, Universiti Kebangsaan Malaysia, Bangi 43600, Malaysia
}

\begin{abstract}
The aim of this paper is to describe a split S-shaped composite meta atom which shows double negative characteristics at resonance frequency. The proposed meta-atom structure exhibits an almost $3.70 \mathrm{GHz}$ bandwidth when the operating frequency from 8 to $14 \mathrm{GHz}$ (X-band). In this study, the ring width, split width, size of substrate material, and the substrate material itself are varying to investigate their effect on the resonance frequencies. Metal strips of the outer resonator are the splits and the inner ring resonator is designed in a way that it forms a split S-shaped structure on the epoxy resin fibre (FR-4) substrate material. The CST Microwave Studio electromagnetic simulator software was used for the design and simulation purposes, and an Agilent N5227A vector network analyser was used for practical measurements.
\end{abstract}

Key words: Capacitance, DNG, inductance, meta atom.

\section{Introduction}

A meta atom is an artificially-engineered material, in which the metallic elements are arranged in a repeating pattern. These meta-atoms exhibit some inaccessible electromagnetic properties, which are very hard to find in naturally-existing, conventional materials. A negative permittivity, permeability and smaller wave length than the target wave length for a specific application are the extraordinary phenomena of the meta atom. A meta atom with negative permittivity $(\varepsilon)$ and permeability ( $\mu$ ) was first shown by Veselago et al. in 1968 [1]. After a long time, a material successfully displaying simultaneously negative permittivity $(\varepsilon)$ and permeability $(\mu)$ was invented by Smith et al. in 2000 [2]. A material with either negative permittivity or permeability $(\varepsilon<0$ or $\mu<0)$ is called a single negative metamaterial. When the values of permittivity and permeability are near zero $(\varepsilon \approx 0$ and $\mu \approx 0$ ) over a specific frequency range, the material is specified as a near-zero refractive index metamaterial. Moreover, a material with simultaneous negative permeability and permittivity $(\varepsilon<0$ and $\mu<0)$ can be characterised as a double negative metamaterial. Since the last century, various structural meta-atom materials have been utilized for several applications, such as resonators, the electromagnetic absorber [3], electromagnetic band gap, filters [4], SAR reduction, invisible clocking operation [5], antenna design [6], biomedical applications, super-lens, waveguides, etc. Nowadays, because of a large bandwidth, high transmission capacity, and short-range features, many different alphabetical meta-atom structures are used for X-band applications.

A rectangular "U-shaped" metamaterial, which displayed left-handed attributes at around 5, 6, and $11 \mathrm{GHz}$ for various

*e-mail: rashed@ukm.edu.my

Manuscript submitted 2016-08-30, revised 2016-10-27, initially accepted for publication 2016-11-02, published in August 2017. array structures in the orthogonal position, was shown by Mallik et al. in 2013 [7]. Moreover, a "Z-shaped" meta atom working only in a single band with a single negative property was introduced by Dhouibi et al. in 2012 [8]. A "V-shaped" metamaterial structure, displaying a $450 \mathrm{MHz}$ bandwidth from 8.05 to $8.50 \mathrm{GHz}$, was presented by Ekmekci et al. in 2007 [9]. Later, an "S-shaped", $15 \times 15 \mathrm{~mm}$ chiral metamaterial for $\mathrm{X}$ and $\mathrm{Ku}$ bands, yet with the effective medium ratio less than 4, was designed by Zhimou et al. in 2015 [10]. Furthermore, a "П-shaped" metamaterial applicable for X-band, whose dimensions were $10 \times 10 \mathrm{~mm}$ and the effective medium ratio was less than 4, was exhibited by Islam et al. in 2015 [5]. However, a "ring-shaped" meta atom for wearable microwave meta-skin and cloaking effects with a range from 8.0 to $10 \mathrm{GHz}$ was suggested by Yang et al. in 2016 [11]. A modified double negative "Z-shaped" metamaterial was developed for wideband operations, but the bandwidth was $2.17 \mathrm{GHz}$ (from 7.87 to $10.04 \mathrm{GHz}$ ). This metamaterial structure, compact in size and applicable for $\mathrm{C}$ - and $\mathrm{X}$-band applications, was proposed by Hasan et al. in 2016 [12].

In this paper, the designed meta-atom structure is comprised of a split S-shaped ring resonator with an outer square-shaped ring resonator made out of copper. The proposed unit cell exhibits resonances at X-band with negative refractive index from 8.0 to $11.70 \mathrm{GHz}$ and 11.78 to $14.0 \mathrm{GHz}$, i.e. the bandwidths cover $3.70 \mathrm{GHz}$ and $2.22 \mathrm{GHz}$, respectively. The proposed meta-atom unit cell shows a larger bandwidth than the reference prototypes [8-12] and exhibits double negative characteristics of the resonance frequency. Besides, here a parametric study has been performed to demonstrate the effects of inductance and capacitance on resonance frequencies. By increasing the length or width of the metal strip, the inductive effect is raised and the LC resonance frequency is decreased. Consequently, the splits are creating capacitance, but with an increase of split width sequentially, the capacitive effect is reducd and the LC 
resonant frequency is increased. Therefore, the inductive and capacitive effects are created by varying the ring width $(\mathrm{d} 1, \mathrm{~d} 2)$, split width (g), and size of substrate material, using different substrate materials, what is elaborately discussed using tables and figures in the results section. The parameters of the proposed meta-atom unit cell are shown in Table 1.

Table 1

Design parameters of split S-shape meta-atom unit cell

\begin{tabular}{|c|c|c|c|}
\hline Parameters & $\begin{array}{c}\text { Dimensions } \\
(\mathrm{mm})\end{array}$ & Parameters & $\begin{array}{c}\text { Dimensions } \\
(\mathrm{mm})\end{array}$ \\
\hline $\mathrm{a}$ & 10 & $\mathrm{~d}$ & 0.5 \\
\hline $\mathrm{b}$ & 10 & $\mathrm{~g}$ & 0.5 \\
\hline $\mathrm{L}$ & 8.0 & $\mathrm{G}$ & 0.3 \\
\hline $\mathrm{w}$ & 8.0 & $\mathrm{~h}$ & 0.035 \\
\hline
\end{tabular}

Epoxy resin fibre is used as substrate material, where its dielectric constant, loss tangent and thickness are 4.5, 0.002, and $1.60 \mathrm{~mm}$, respectively. However, the dimensions of the unit cell are $10 \times 10 \mathrm{~mm}$ and the unit cell structure is described in Fig. 1a.

a)

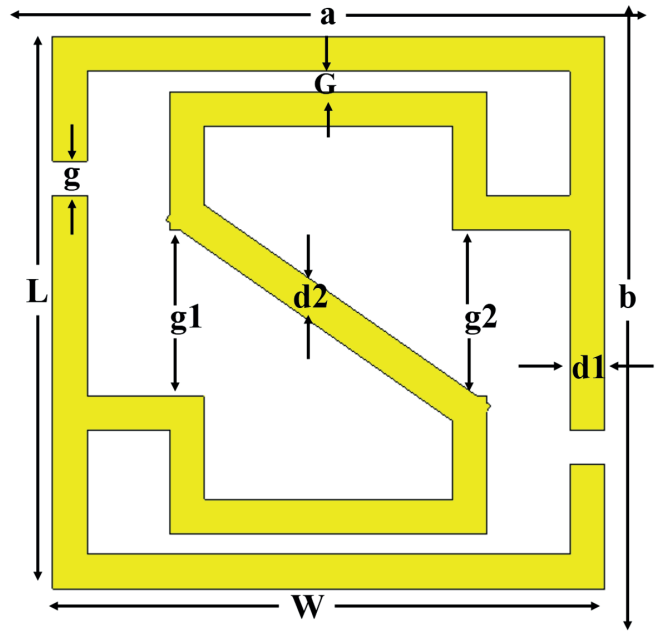

b)

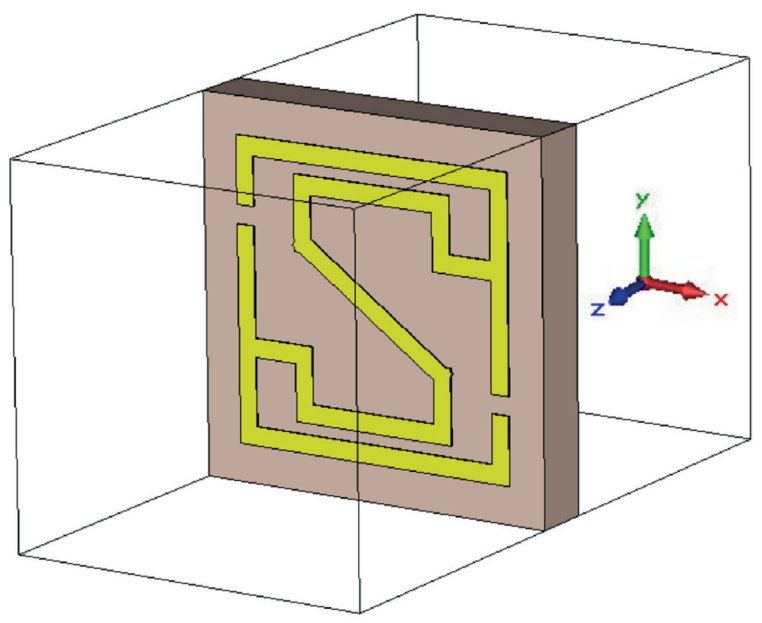

Fig. 1. a) Proposed unit-cell structure, b) boundary condition for the proposed unit cell

\section{Methodology}

Finite integration technique (FIT), based on the CST Microwave Studio electromagnetic simulator, has been used for observing the reflection coefficient $\left(\mathrm{S}_{11}\right)$ and transmission coefficient $\left(\mathrm{S}_{21}\right)$ of the proposed meta-atom unit cell to calculate the effective medium parameters. In this simulation and measurement technique, the unit-cell structure is placed between two waveguide ports and the electromagnetic wave propagation is set to the $\mathrm{z}$ direction. In the $\mathrm{x}$ and $\mathrm{y}$ directions, perfect electric and perfect magnetic boundaries are considered. A frequency domain solver with a tetrahedral mesh has been utilized for the simulation purposes. However, the operating frequency range for the proposed meta-atom structure is from 8.0 to $14.0 \mathrm{GHz}$, whereas the impedance has been set to $50 \Omega$.

To understand the electromagnetic behaviour of the proposed unit cell, the effective medium parameters are separated from the reflection coefficient $\left(\mathrm{S}_{11}\right)$ and transmission coefficient $\left(\mathrm{S}_{21}\right)$. Therefore, effective permittivity $\left(\varepsilon_{r}\right)$, permeability $\left(\mu_{r}\right)$ and refractive index $\left(\eta_{\mathrm{r}}\right)$ are acquired individually by:

$$
\begin{aligned}
\varepsilon_{r} & =\frac{c}{j \pi f d} \times\left\{\frac{\left(1-S_{21}-S_{11}\right)}{\left(1+S_{21}+S_{11}\right)}\right\}, \\
\mu_{r} & =\frac{c}{j \pi f d} \times\left\{\frac{\left(1-S_{21}+S_{11}\right)}{\left(1+S_{21}-S_{11}\right)}\right\}, \\
\text { and } \eta_{r} & =\frac{c}{j \pi f d} \sqrt{\left\{\frac{\left(S_{21}-1\right)^{2}-S_{11}^{2}}{\left(S_{21}+1\right)^{2}-S_{11}^{2}}\right\} .}
\end{aligned}
$$

For the measurement purposes, a prototype of $10 \times 10 \mathrm{~mm}$ unit cell has been fabricated. The measurement was performed in an open-space environment by placing the prototype between the waveguide ports. An Agilent N5227A vector network analyser was utilized to determine the S-parameters of the split S-shaped unit cell. However, Agilent N4694-60001 is also used for calibration purposes, so that the measurement can be performed accurately.

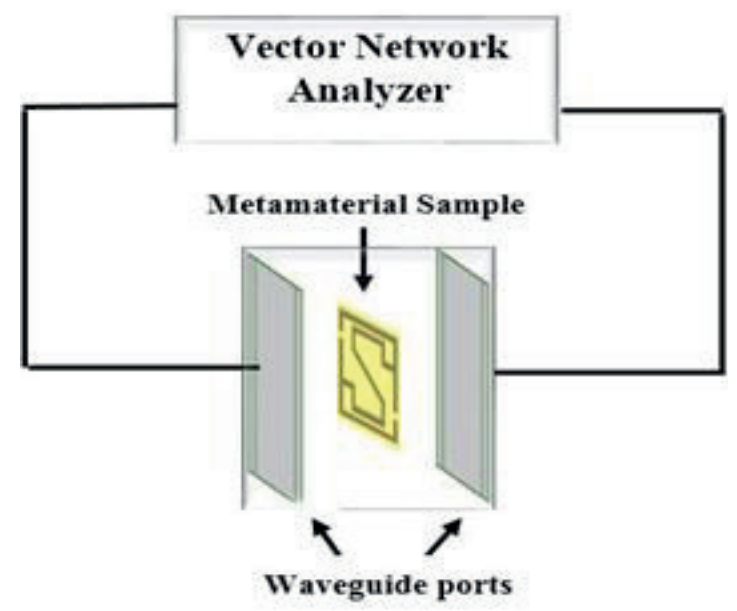

Fig. 2. Experimental setup for the measurement of the S-parameters 
a)

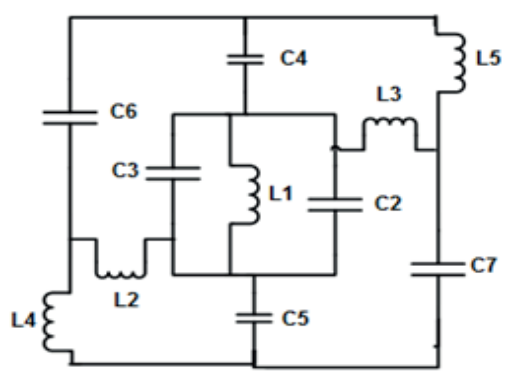

b)

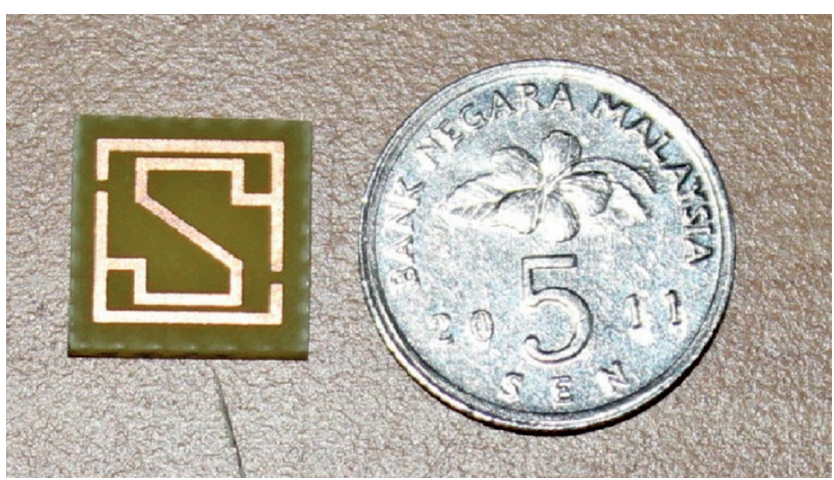

Fig. 3. a) Equivalent circuit model of the split S-shaped structure, (b) fabricated geometry of the proposed meta-atom unit cell

2.1. Equivalent circuit model of the proposed meta atom. The proposed meta atom consists of passive LC circuits, where the resonance frequency is

$$
f=\frac{1}{2 \pi \sqrt{L C}}
$$

Here, $\mathrm{L}$ and $\mathrm{C}$ are the total inductance and capacitance, respectively. Inductances are formed by the metal strip and the capacitances are formed by the gaps in the designed structure. When the applied electromagnetic wave is propagating along the structure, the electric resonances are produced by the coupling between the gaps and electric fields. Similarly, magnetic resonances are formed by the coupling between the magnetic fields and the loops. The total inductance $\mathrm{L}$ for the proposed meta atom can be obtained by

$$
L=0.01 \times \mu_{0}\left\{\frac{2(d+g+h)^{2}}{(2 w+g+h)^{2}}+\frac{\sqrt{(2 w+g+h)^{2}+l^{2}}}{(d+g+h)}\right\} t .
$$

However, the total capacitance $\mathrm{C}$ of the proposed meta atom can be calculated by

$$
C=\varepsilon_{0}\left[\frac{(2 w+g+h)}{2 \pi(d+h)^{2}} \ln \left\{\frac{2(d+g+h)}{(a-l)}\right\}\right] t .
$$

where the free-space permeability is $\mu_{0}=4 \pi \times 10^{-7} \mathrm{H} / \mathrm{m}$ and the free-space permittivity is $\varepsilon_{0}=8.85 \times 10^{-12} \mathrm{~F} / \mathrm{m}$.

In Fig. 3a the series and shunt branch of the circuit are responsible for inductance and capacitance. The splits maintain capacitive effect, denoted by C1, C2, C3, C4, C5, C6, and C7 in the circuit. Similarly, the metal strips create the inductive effect symbolized by L1, L2, L3, L4, and L5. Adding more split in the meta-atom structure produces a small phase delay and reduces the capacitive effect. Due to a reduced capacitance, the split S-shape unit cell shows resonance at a higher frequency. The fabricated prototype of the proposed meta-atom unit cell is shown in Fig. $3 b$.

\section{Results and discussion}

The current distribution of the unit cell at $11.92 \mathrm{GHz}$ is shown in Fig. 4a. The current is flowing in a forward and reverse direction in the same metal resonator strip of the unit cell because of the dissimilar geometry of the proposed structure. The flow of opposite current in the inner and outer surfaces causes a band-stop at the resonance frequency range. Figure $4 \mathrm{~b}$ displays resonance at $12.0 \mathrm{GHz}$ in a simulation, but the measured

a)

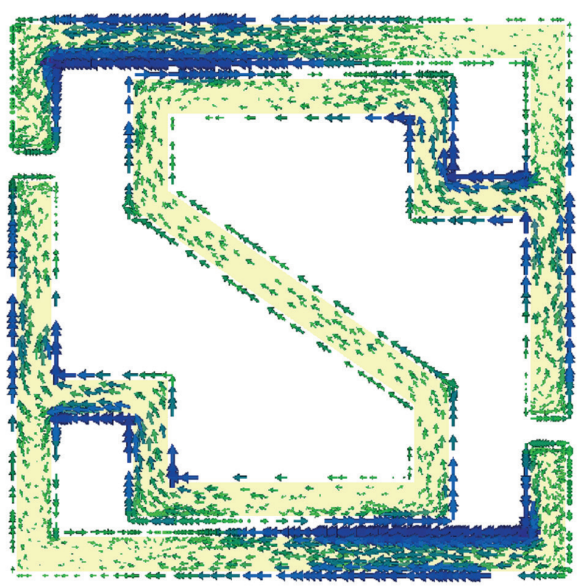

b)

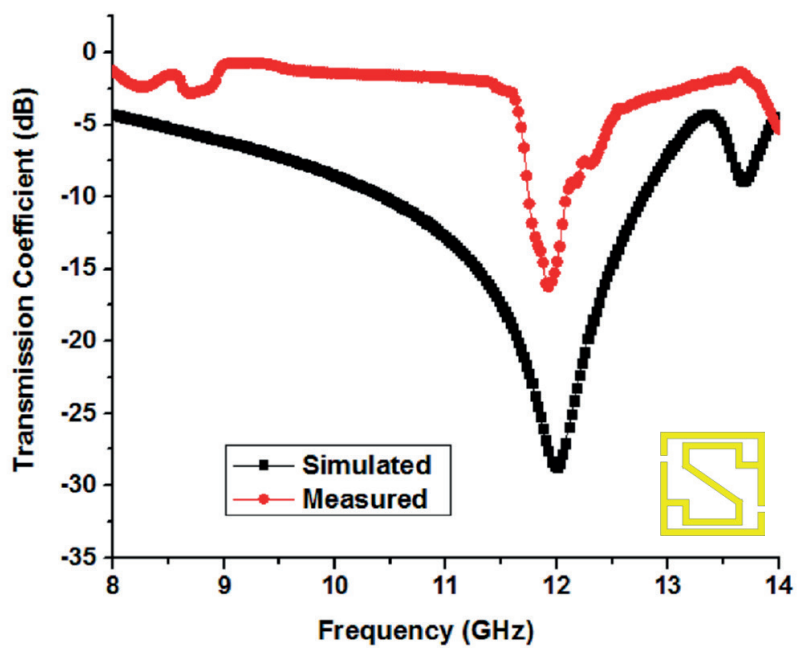

Fig. 4. a) Surface current distribution at $11.92 \mathrm{GHz}$, b) transmittance $\left(\mathrm{S}_{21}\right)$ curve of proposed split S-shape meta-atom unit cell 
a)

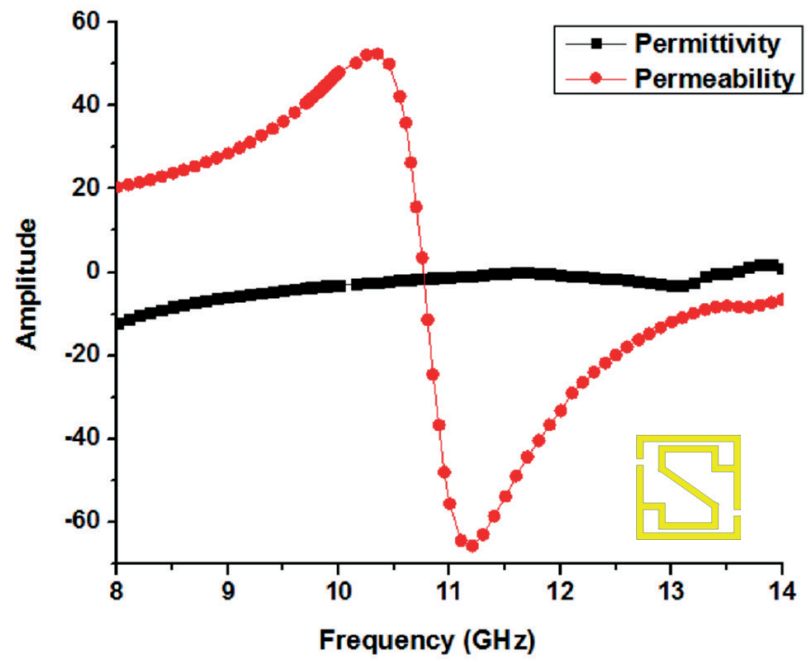

b)

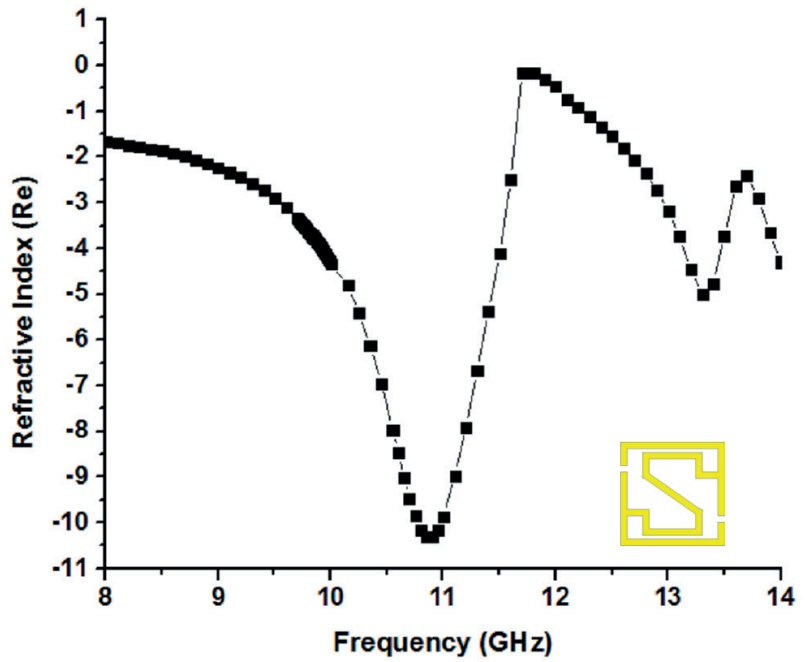

Fig. 5. Real magnitude of: a) effective permittivity $(\varepsilon)$ and permeability $(\mu)$ vs. frequency, b) effective refractive index ( $\eta)$ vs. frequency of the unit cell

results in Fig. 4b show resonance to be at $11.92 \mathrm{GHz}$ (X-band). Although the simulated and measured resonance were almost corresponding, the results of the measurement were slightly shortened and shifted in relation to the simulated results. This shift usually occurs due to a free space measurement process or fabrication errors.

Figure 5 indicates the real value of the effective medium parameters. As shown in Fig. 5a, negative permeability $(\mu)$ is present from 10.70 to $14.0 \mathrm{GHz}$, i.e. covers a bandwidth of 3.30 GHz. Normally, the frequency ranges at which the permeability of the unit cell is under negative current can keep up with the applied field at lower frequencies, but at higher frequencies the current cannot cope with the applied field and starts lagging. Moreover, from 8.0 to $14.0 \mathrm{GHz}$ the values of permittivity ( $\varepsilon$ ) are negative, but almost near zero. Here it is revealed that there is a variation between the permeability and permittivity due to the polarization effect caused by the internal manner of the material. When electromagnetic waves enter anisotropic materials at unequal lattice axes, the polarization effect occurs inside the materials. As a result, the values of permeability and permittivity change due to changes in the design. The refractive index curve is also affected by the polarization like the same procedure. If the unit cell permittivity and permeability simultaneously appear to be negative, then the refractive index curve would be negative. However, the proposed unit cell structure exhibits simultaneously negative permittivity and permeability in a range from 10.70 to $14.0 \mathrm{GHz}$. As expected, the proposed meta-atom unit cell shows the real magnitude of negative re-

Table 2

Real values of effective medium parameters at resonance frequency of the unit cell

\begin{tabular}{|c|c|c|c|}
\hline $\begin{array}{c}\text { Resonance } \\
\text { frequency }\end{array}$ & $\begin{array}{c}\text { Value of } \\
\text { permittivity }\end{array}$ & $\begin{array}{c}\text { Value of } \\
\text { permeability }\end{array}$ & $\begin{array}{c}\text { Value of } \\
\text { refractive index }\end{array}$ \\
\hline $11.92 \mathrm{GHz}$ & -0.53 & -34.23 & -0.41 \\
\hline
\end{tabular}

fractive index $(\eta)$ from 8.0 to $11.70 \mathrm{GHz}$ and from 11.78 to 14.0 GHz, covering a bandwidth of $3.70 \mathrm{GHz}$ and $2.22 \mathrm{GHz}$, respectively (Fig. 5b). At a resonance of $11.92 \mathrm{GHz}$ the effective permittivity, permeability, and the refractive index are negative, and their values are presented in Table 2. As a result, this split $\mathrm{S}$-shape meta-atom structure can be characterized as a double negative (DNG) meta atom.

\subsection{Parametric studies analysis.}

A. Consequence of changing the ring width. The effect of changing the width of the outer ring metal strip on resonance is presented in Fig. 6a and in Table 3. Table 3 shows that with an increase of the metal ring width, the resonance frequency is shifted towards a lower frequency. Actually, the outer ring metal strips are responsible for creating the inductance. When the width of the metal strip is increased, the inductive effect is also increased. As a result, due to the inductive effect, the LC resonance frequency is decreased.

Table 3

Relation between the width of the outer ring (d1) and resonance frequency

\begin{tabular}{|c|c|c|}
\hline $\begin{array}{c}\text { Metal strip width } \\
(\mathrm{mm})\end{array}$ & $\begin{array}{c}\text { Resonance } \\
\text { frequency }(\mathrm{GHz})\end{array}$ & $\begin{array}{c}\text { Max. value of } \\
\text { transmittance }\end{array}$ \\
\hline 0.3 & 12.28 & -27.18 \\
\hline 0.5 & 12.00 & -28.71 \\
\hline 0.7 & 11.70 & -30.15 \\
\hline
\end{tabular}

From Table 4, resonance is at $12.15 \mathrm{GHz}, 12.0 \mathrm{GHz}$, and $11.80 \mathrm{GHz}$ for the inner ring width of $0.3 \mathrm{~mm}, 0.5 \mathrm{~mm}$, and $0.7 \mathrm{~mm}$, respectively. By increasing the inner ring width $(\mathrm{d} 2)$, the gap $(\mathrm{G})$ between the outer and inner ring is decreased. When the gap between the two is decreased, the inductive effect is also increased, and the resonance frequency is de- 
a)

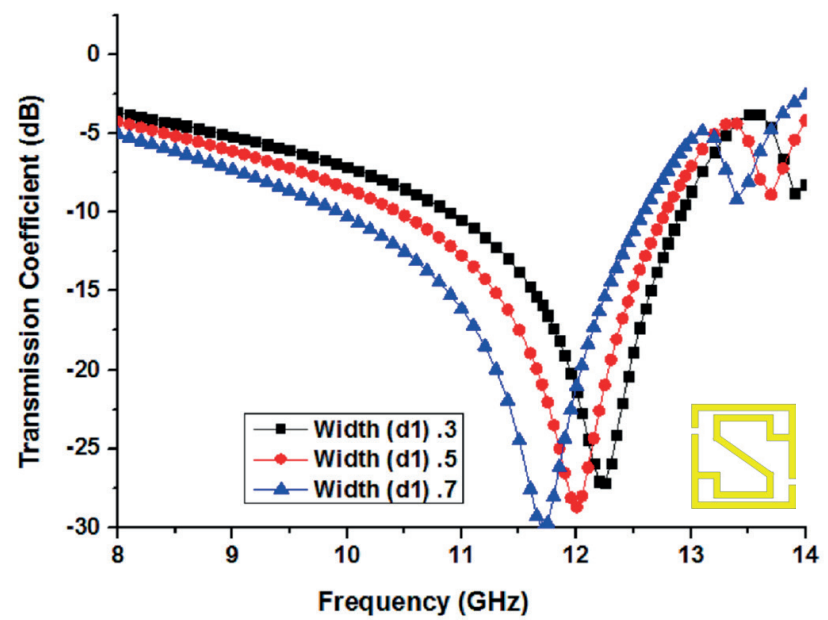

b)

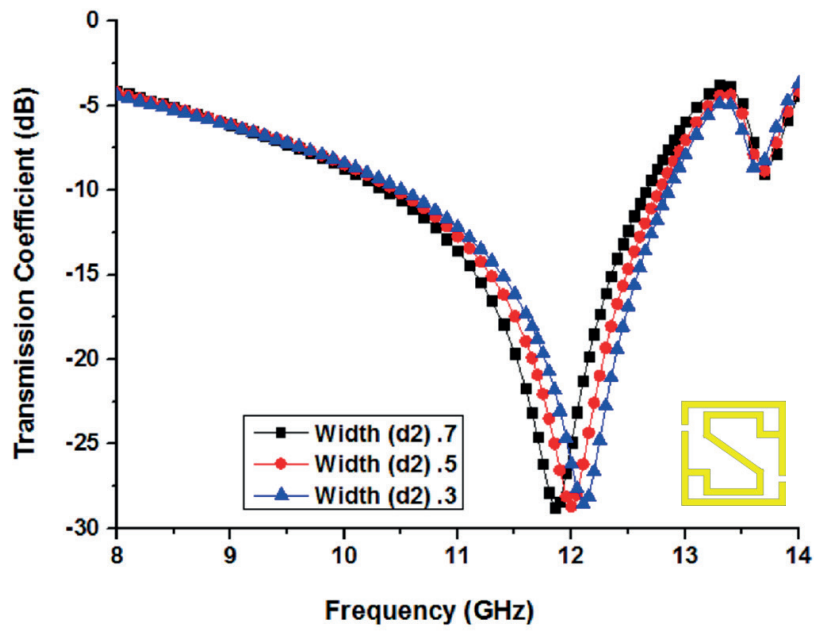

Fig. 6. Relation between the widths of: a) the outer ring (d1) vs. resonance frequency, b) the inner s-shape ring (d2) vs. resonance frequency

clining. Similarly, by decreasing the width and increasing the gap between the rings, the capacitive effect can be raised for the proposed unit cell.

Table 4

Relation between the width of the inner ring (d2) and resonance frequency

\begin{tabular}{|c|c|c|}
\hline $\begin{array}{c}\text { Metal strip } \\
\text { width }(\mathrm{mm})\end{array}$ & $\begin{array}{c}\text { Resonance } \\
\text { frequency }(\mathrm{GHz})\end{array}$ & $\begin{array}{c}\text { Max. value of } \\
\text { transmittance }\end{array}$ \\
\hline 0.3 & 12.15 & -27.88 \\
\hline 0.5 & 12.00 & -28.71 \\
\hline 0.7 & 11.80 & -28.58 \\
\hline
\end{tabular}

B. Effects of varying the split width. Table 5 shows the relation between the split width and resonance frequency. Here, the resonances are increasing with an increase of the split $(\mathrm{g})$

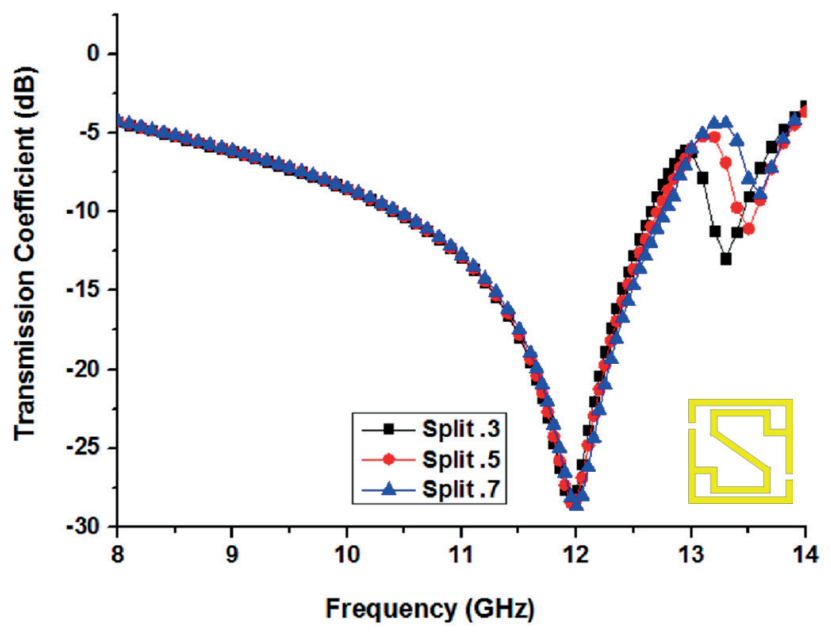

Fig. 7. Relation between the width of the split and resonance frequency width. By increasing the split (g), the coupling capacitance can be reduced, which leads to resonance at a higher frequency. Figure 7 is a graphical representation of Table 5. In Fig. 7 it can be seen that when the split width is at $0.3 \mathrm{~mm}, 0.4 \mathrm{~mm}$, and $0.5 \mathrm{~mm}$, the resonance is $11.90 \mathrm{GHz}, 11.95 \mathrm{GHz}$, and $12.0 \mathrm{GHz}$, respectively.

Table 5

Relation between the width of the split (g) and resonance frequency

\begin{tabular}{|c|c|c|}
\hline $\begin{array}{c}\text { Split width } \\
(\mathrm{mm})\end{array}$ & $\begin{array}{c}\text { Resonance } \\
\text { frequency }(\mathrm{GHz})\end{array}$ & $\begin{array}{c}\text { Max. value of } \\
\text { transmittance }\end{array}$ \\
\hline 0.3 & 11.90 & -28.35 \\
\hline 0.4 & 11.95 & -28.47 \\
\hline 0.5 & 12.00 & -28.71 \\
\hline
\end{tabular}

C. Outcome of substrate material. Three different sizes of unit cells $(8 \times 8 \mathrm{~mm}, 10 \times 10 \mathrm{~mm}$, and $12 \times 12 \mathrm{~mm})$ are tested to investigate the effect of the unit cell size on the resonance frequency. From Table 6, the resonance frequencies are shifted to the lower frequencies with the increase of the unit cell size. Similarly, for a smaller size of the unit cell the resonance appears at higher frequencies. Moreover, for $8 \times 8 \mathrm{~mm}, 10 \times 10 \mathrm{~mm}$, and $12 \times 12 \mathrm{~mm}$ unit cells, the resonance frequencies are $13.25 \mathrm{GHz}$, 12.0 GHz, and $8.60 \mathrm{GHz}$, respectively.

Table 6

Relationship between the unit-cell dimensions and resonance frequency

\begin{tabular}{|c|c|c|}
\hline $\begin{array}{c}\text { Unit cell } \\
\text { dimension }\left(\mathrm{mm}^{2}\right)\end{array}$ & $\begin{array}{c}\text { Resonance } \\
\text { frequency }(\mathrm{GHz})\end{array}$ & $\begin{array}{c}\text { Max. value of } \\
\text { transmittance }\end{array}$ \\
\hline $8 \times 8$ & 13.25 & -32.28 \\
\hline $10 \times 10$ & 12.00 & -28.71 \\
\hline $12 \times 12$ & 8.60 & -18.93 \\
\hline
\end{tabular}


a)

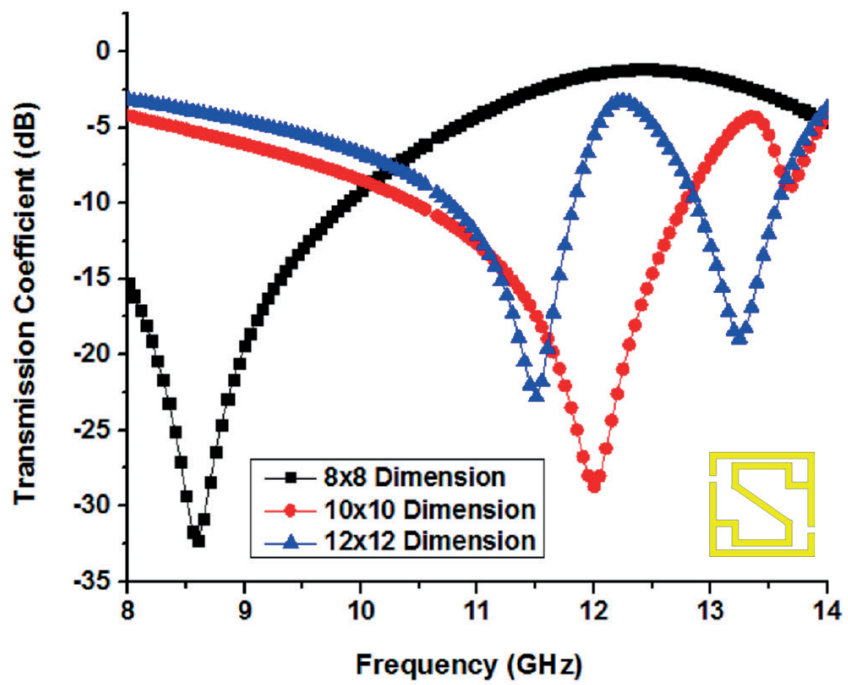

b)

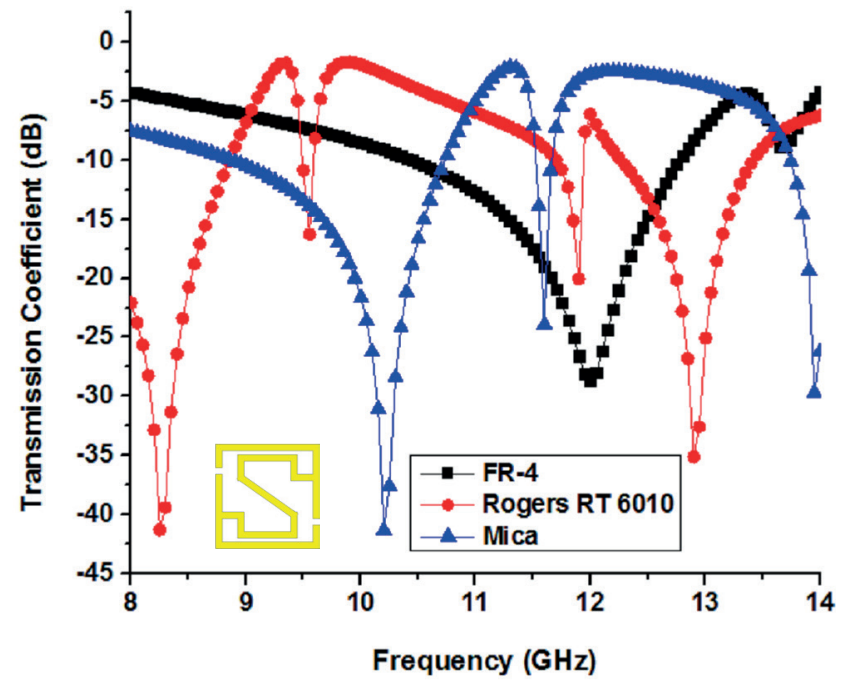

Fig. 8. Relation between the effects of substrate materials: a) dimension vs. resonance frequency, b) variation vs. resonance frequency

Figure $8 \mathrm{~b}$ represents the effect of different types of substrate materials on resonance frequency. In addition, the dielectric constant and tangent loss of the FR-4, Rogers RT 6010, and Mica is 4.5, 10.6, and 5.4 and $0.002,0.0023$, and 0.003 , respectively. For the substrate material, the dielectric constant is a very important factor. If the dielectric constant is increased, then the substrate material conductivity is decreased. The dielectric constant of a material depends on the material's internal structure. When electromagnetic waves propagate through a material, its electric and magnetic fields oscillate in a sinusoidal pattern, and their velocity depends on the material's electrical conductivity, which, again, depends on the material's internal structure. Electrical signals travel through the material with a varying relative speed, dependng on the sort of interaction with the material's internal structure. However, the variation in the inner metallic pattern causes different results in the transmission characteristics. From Table 7, resonance occurs at $12.0 \mathrm{GHz}$ for FR-4, at $10.20 \mathrm{GHz}$ and $13.95 \mathrm{GHz}$ for Mica, and at $8.25 \mathrm{GHz}$, $11.90 \mathrm{GHz}$, and $12.90 \mathrm{GHz}$ for Rogers RT 6010.

Table 7

Relationship between the different substrate material and resonance frequency

\begin{tabular}{|c|c|c|c|}
\hline $\begin{array}{c}\text { Substrate } \\
\text { material }\end{array}$ & $\begin{array}{c}\text { Dielectric } \\
\text { constant }\end{array}$ & $\begin{array}{c}\text { Resonance } \\
\text { frequency }\end{array}$ & $\begin{array}{c}\text { Max. value of } \\
\text { transmittance }\end{array}$ \\
\hline Fr-4 & 4.5 & $12.00 \mathrm{GHz}$ & -28.71 \\
\hline Mica & 5.4 & $10.20 \mathrm{GHz}$ & -41.37 \\
& & $13.95 \mathrm{GHz}$ & -29.71 \\
\hline Rogers RT & 10.2 & $8.25 \mathrm{GHz}$ & -41.31 \\
6010 & & $11.90 \mathrm{GHz}$ & -20.05 \\
& & $12.90 \mathrm{GHz}$ & -35.15 \\
\hline
\end{tabular}

From Table 8, the bandwidth of the designed meta atom is $3.70 \mathrm{GHz}$, which is almost threefold of that in [8]. However, the bandwidth has increased by almost $12.16 \%, 61.89 \%, 28.38 \%$, and $58.64 \%$ of those in [9], [10], [11], and [12], respectively.

Table 8

Comparison of the proposed meta atom with previous researches

\begin{tabular}{|l|l|c|}
\hline References & \multicolumn{1}{|c|}{ Bandwidth $(\mathrm{GHz})$} & $\begin{array}{c}\text { Bandwidth increase of } \\
\text { the proposed meta atom }\end{array}$ \\
\hline $\begin{array}{l}\text { Dhouibi } \\
\text { et al. [8] }\end{array}$ & $\begin{array}{l}5.40 \text { to } 6.80 \mathrm{GHz} \\
\text { (bandwidth of } 1.40 \mathrm{GHz} \text { ) }\end{array}$ & $37.84 \%$ \\
\hline $\begin{array}{l}\text { Ekmekci } \\
\text { et al. [9] }\end{array}$ & $\begin{array}{l}8.05 \text { to } 8.50 \mathrm{GHz} \\
\text { (bandwidth of } 0.45 \mathrm{GHz} \text { ) }\end{array}$ & $12.16 \%$ \\
\hline $\begin{array}{l}\text { Zhou } \\
\text { et al. [10] }\end{array}$ & $\begin{array}{l}9.71 \text { to } 12 \mathrm{GHz} \\
\text { (bandwidth of } 2.29 \mathrm{GHz} \text { ) }\end{array}$ & $61.89 \%$ \\
\hline $\begin{array}{l}\text { Yang } \\
\text { et al. [11] }\end{array}$ & $\begin{array}{l}9.30 \text { to } 10.35 \mathrm{GHz} \\
\text { (bandwidth of } 1.05 \mathrm{GHz} \text { ) }\end{array}$ & $28.38 \%$ \\
\hline $\begin{array}{l}\text { Hasan } \\
\text { et al. [12] }\end{array}$ & $\begin{array}{l}7.87 \text { to } 10.04 \mathrm{GHz} \\
\text { (bandwidth of } 2.17 \mathrm{GHz} \text { ) }\end{array}$ & $58.64 \%$ \\
\hline $\begin{array}{l}\text { Proposed } \\
\text { meta atom }\end{array}$ & $\begin{array}{l}8 \text { to } 11.70 \mathrm{GHz} \\
\text { (bandwidth of } 3.70 \mathrm{GHz} \text { ) }\end{array}$ & $100 \%$ \\
\hline
\end{tabular}

\section{Conclusion}

A split S-shape meta-atom structure which exhibits double negative properties, designed on an epoxy resin fibre substrate material is introduced in the paper. The proposed unit cell resonance is found to be at $11.92 \mathrm{GHz}$ and displays an almost $3.70 \mathrm{GHz}$ bandwidth in the major portion of the X-band. The measured results show a good conformity with the numerical results. Moreover, X-band is applicable for the satellite communication system. Besides, it is relevant for oceanic vessel activity control, defense tracking, military climate radar technology, etc. Through parametric studies, it is clear that the parameters have 
a strong influence on the resonant frequencies. If there appears a necessity to change the resonance, then these parametric studies become truly important.

\section{REFERENCES}

[1] V.G. Veselago, "The electrodynamics of substances with simultaneously negative values of $\varepsilon$ and $\mu$ ", Sov. Phys. 10, 509-514 (1968).

[2] D.R. Smith, W.J. Padilla, D.C. Vier, S.C. Nemat-Nasser, and S. Schultz, "Composite medium with simultaneously negative permeability and permittivity", Phy. Rev. Lett. 84, 4184-4187 (2000).

[3] X. Liu, C. Lan, Q. Zhao, and J. Zhou, "Dual band metamaterial perfect absorber based on artificial dielectric molecules", Sci. Rep. 6, Article No. 28906 (2016).

[4] C.F. Fang, J.S. Gao, and H. Liu, "A novel metamaterial filter with stable passband performance based on frequency selective surface", AIP Advances 4, 077114 (2014).

[5] S.S. Islam, M.R.I. Faruque, and M.T. Islam, "A near zero refractive index metamaterial for electromagnetic invisibility cloaking operation", Materials 8, 4790-4804 (2015).

[6] A.T. Abed and M.S.J. Singh, "Slot antenna single layer fed by step impedance strip line for Wi-Fi and Wi-Max applications", Elec. Lett. 52 (14), 1196-1198 (2016).
[7] A. Mallik, A.S. Kundu, and M.O. Goni, "Design of a novel two-rectangular U-shaped double negative metamaterial", 2013 International Conference on Informatics, Electronics \& Vision, (2013).

[8] A. Dhouibi, S.N. Burokur, A.D. Lustrac, and A. Priou, "Study and analysis of an electric Z-shaped meta-atom", Adv. Electromagnetics 1 (2) (2012).

[9] E. Ekmekci and G.T. Sayan, "Investigation of effective permittivity and permeability for a novel V-shaped metamaterial using S-parameters", 5th International Conference on Electrical and Electronics Engineering, (2007).

[10] Z. Zhou and H. Yang, "Triple-band asymmetric transmission of linear polarization with deformed S-shape bilayer chiral metamaterial", Appl. Phys. A 119 (1), 115-119 (2015).

[11] S. Yang, P. Liu, M. Yang, Q. Wang, J. Song, and L. Dong, "From flexible and stretchable meta-atom to metamaterial: a wearable microwave meta-skin with tunable frequency selective and cloaking effects", Sci. Rep. 6, Article No. 21921 (2016).

[12] M.M. Hasan, M.R.I. Faruque, S.S. Islam, and M.T. Islam, "A new compact double-negative miniaturized metamaterial for wideband operation", Materials 9 (10), 830 (2016).

[13] M.R.I. Faruque, M.M. Hasan, and M.T. Islam, "Wideband $90^{\circ}$ azimuthal miniaturized meta atom with left-handed characteristics", IEEE Antennas and Wireless Propagation Letters PP (99), (2016). 